\title{
Lessons Learned from Implementing a Textbook's Companion Website into a Production Operations Management Course
}

\section{Lt. Col. John P Richards P.E., United States Military Academy}

Lieutenant Colonel John Richards currently serves as an Assistant Professor at the United States Military Academy in the Department of Systems Engineering, focusing on topics in project and operations management. He is a career Army Engineer Officer and previously taught in the Department of Civil and Mechanical Engineering at the United States Military Academy. He holds masters degrees in both Engineering Management (University of Missouri-Rolla) and Civil Engineering (University of ColoradoBoulder) as well as a bachelors degree in Civil Engineering from Bucknell University. He is a registered Professional Engineer in the state of Colorado. 


\title{
Lessons Learned from Implementing a Textbook's Companion Website into a Production Operations Management Course
}

\begin{abstract}
The availability and use of online textbooks or companion websites for textbooks coupled to engineering management courses has been increasing. With this increase, the effective integration of assignments conducted via these online textbook companion tools can increase student engagement with the course material as well as within the classroom to enhance the student learning experience. But experience shows that use of these online tools can seem ineffective at best or a waste of time from a student perspective. Student feedback often expresses displeasure with the cost of purchasing access to the companion site, frustration with the precision required to correctly answer quantitative problems, and the tedious nature of completing assignments that they perceive lack connection to the in-class lessons. Successful integration of the companion site into the course that overcomes these obstacles can lead to students perceptions that use of the companion website is value added, not just another tedious task.
\end{abstract}

For these reasons, the course director of the Production Operations Management course at the United States Military Academy utilized student assessment data, end of course feedback, and pre/post course student surveys to assess the effectiveness of use of assignments through the textbook companion website. This assessment drove changes in the implementation and integration of the companion website into the course in order to increase student engagement with the textbook material and classroom discussion. The changes focused on both frequency and content of the online assignments conducted through the textbook companion site. Implementation of these changes showed a dramatic improvement in student attitudes and performance over five semesters.

This paper discusses the assessments that led to the changes in use of the textbook companion website as well as specific practices and recommendations for implementation of textbook companion website assignments. Use of textbook companion websites can positively impact student interaction and achievement.

Introduction

The use of the companion website for the Production Operations Management course in the Engineering Management program at the United States Military Academy (USMA) was driven by both policy and pedagogy. It is the Academy's policy that all students must purchase the assigned textbook for each of their courses. This policy was easy to enforce when the book ordering and delivery process was centrally managed by the Academy. Recent changes allowing students to purchase their textbooks in various forms (hardcopy, digital, etc.) from any source have made it more challenging to enforce the textbook policy. Additionally, the explosion in ebook availability and the pitfalls of sharing eBook passwords and access that may violate copyright laws makes the situation even more complex.

From a pedagogical standpoint, research shows that student learning improves when they come to class having completed the assigned reading, which allows a student to achieve the "primary 
intellectual objective is to cover course content - the specific facts, theories, or procedures under study".[1] Time in the classroom can then be spent working on the "higher-order intellectual objectives of application, analysis, synthesis, and evaluation, it is more important that instructors use classes (1) to clarify especially difficult concepts or procedures, (2) to illustrate content using engaging examples, and (3) to emphasize the connections between concepts." [1] There is also the struggle to get students to read. "We need to teach students how to read - how to read with understanding, how to think about the purpose of the author, about relationships to earlier learning, about how they will use what they’ve read." [2]

To achieve these objectives, the Course Director for the Production Operations Management course decided to implement the textbook's companion course for a portion of the assignments in the course. The website can be either purchased as a standalone online product, which includes a downloadable textbook, or as a supplement to a hardcopy product. Either way, there is a significant cost to each student associated with purchasing access to the companion website. Students expect to get value for their investment in the textbook companion website. This paper will explain the evolution of the use of the companion website, document and describe the improvements made in implementation, and make recommendations on how to utilize textbook companion websites to enhance student learning and attainment.

To maintain consistency of the assessment of the implementation of the textbook companion website over time, this paper looks at data for one professor teaching the course across five semesters (not all consecutive). In three of the five semesters, this professor was the only one teaching the course. This professor was the course director the two other semesters the course was with other faculty members and the data from those faculty members has been excluded from this study. Also, the same textbook (through two editions) with the same companion website was used for the five semesters observed in this study.

Initial iteration of implementation of the textbook companion website

The first two semesters of implementation of the textbook's companion website for this course were the Spring terms of 2015 and 2016 (noted as Academic Terms 15-2 and 16-2 at USMA); the course was not taught by the professor studied in the Fall of 2016 (Academic Term 16-1). Most of the forty lessons of the course in each term consisted of both qualitative and quantitative material. The format typically included a discussion of a concept or set of concepts then the application of a tool or set of tools to solve problems related to the concept(s). The course director utilized the textbook companion website by assigning questions associated with the readings for each content lesson. The due dates for these assignments were consolidated into three blocks aligned with the three major exams in the course, but organized by lesson, making it clear to which what reading assignment they were linked. Students had the option to either complete the assignments as its associated lesson was taught, or wait until the end of the block and complete all the assignments prior to the exam with the intent that these assignments would support student preparation for the exam. Each block of online assignments was assigned a value of 25 points (for a total of 75 points, or $7.5 \%$ of the course grade) with students earning their grade based on how many of the questions they completed correctly. The questions were both qualitative (concepts) and quantitative (calculations). 


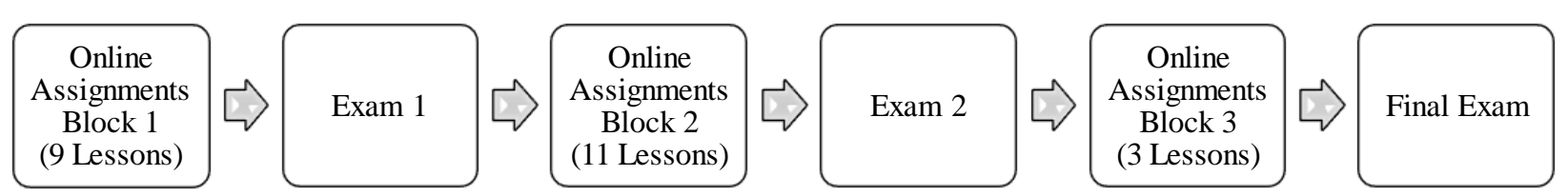

Figure 1. Initial Iteration Layout of Online Assessments (AT15-2)

Assessment

The student grades for each block ( 25 points each) were scaled based on their raw score for the block. Table 1 is a summary of the average of the raw scores, the number of assignments completed by the students, and the points assigned consolidated for each term (note: the difference between the raw score and the points assigned is due to the rounding that occurred at each block so that scores would be entered into the grade book as broken down no further than to $0.5)$. It is interesting to note, that even though every lesson's assignment contributed to the score, students chose to complete on average about $75 \%$ of the assignments.

\begin{tabular}{|c|r|r|r|}
\hline \multicolumn{5}{|c|}{ AT15-2 (Spring 2015) } \\
\hline & Cumulative Raw Score & Total Assignments & Cumulative Points Assigned \\
\hline Max & 210 & 29 & 75 \\
\hline \multirow{2}{*}{ Average } & 154.46 & 22.25 & 55.65 \\
\cline { 2 - 4 } & $73.55 \%$ & $76.72 \%$ & $74.20 \%$ \\
\hline \multicolumn{4}{|c|}{ AT16-2 (Spring 2016) } \\
\hline \\
\cline { 2 - 4 } Max & Cumulative Raw Score & Total Assignments & Cumulative Points Assigned \\
\hline \multirow{2}{*}{ Average } & 226 & 23 & 75 \\
\cline { 2 - 4 } & 132.08 & 16.98 & 54.20 \\
\hline
\end{tabular}

Table 1. Initial Iteration Student Performance Data

The professor provided two opportunities for the students to provide feedback via anonymous free-response comments; mid-course comments submitted on index cards and end-of-course online feedback. The mid-course feedback was collected by the professor in the classroom by having students fill out a notecard anonymously identifying at least one sustain or improve for the course and/or professor. The end-of-course feedback was collected through the Academy's online end-of-course survey in the free text question: "How effective was your instructor in teaching Operations Management and what would you recommend she(he) improve for next time the course is taught?"

Though the students were not asked directly to comment on the use of online assignments in the course in either feedback forum, a number of students commented specifically on the implementation of the textbook's companion website in response to the free response questions. Table 2 shows the number of student responses that included feedback on the use of the companion website and whether it was positive (should be sustained) or negative (should be improved). A significant number of the responses related directly to the implementation of the textbook's companion website with the vast majority of those comments were negative, implying that students were not pleased with how the companion site was being implemented. 


\begin{tabular}{|l|c|r|c|c|c|c|}
\hline \multirow{2}{*}{} & \multicolumn{3}{|c|}{ Mid-Course Feedback } & \multicolumn{2}{c|}{ End of Course Feedback } \\
\cline { 2 - 7 } & Responses & \multicolumn{2}{|c|}{ Rate } & Responses & \multicolumn{2}{c|}{ Rate } \\
\hline AT15-2 & 32 & Overall & Split & 25 & Overall & Split \\
\hline Positive/Sustain & 2 & $6.25 \%$ & $20.00 \%$ & 1 & $4.00 \%$ & $50.00 \%$ \\
\hline Negative/Improve & 8 & $25.00 \%$ & $80.00 \%$ & 1 & $4.00 \%$ & $50.00 \%$ \\
\hline Total & 10 & $31.25 \%$ & & 2 & $8.00 \%$ & \\
\hline & & & & & & \\
\hline AT16-2 & 50 & Overall & Split & 52 & Overall & Split \\
\hline Positive/Sustain & 0 & $0.00 \%$ & $0.00 \%$ & 0 & $0.00 \%$ & $0.00 \%$ \\
\hline Negative/Improve & 8 & $16.00 \%$ & $100.00 \%$ & 8 & $15.38 \%$ & $100.00 \%$ \\
\hline Total & 8 & $16.00 \%$ & & 8 & $15.38 \%$ & \\
\hline
\end{tabular}

Table 2. Initial Iteration Feedback Summary

Most of the specific comments centered on the feeling that the students felt they did not get the value from the companion website that aligned with the high cost as indicated by the following sampling of the comments:

"I do not like [companion website]. It is a waste of time and money"

"The [companion website] is unnecessary and too expensive and not really helpful"

"The online homeworks. I feel like it was an expensive purchase to gain access to the [companion website] site for the amount of points/learning I am getting out of it."

"The only think I would change for next semester is the [companion website], having to pay for the homework when it isn't that helpful just seems like waste."

"I would recommend putting the [companion website] to go with the lessons instead of just a chunk of them at the end"

This data and the specific comments indicated a high level of displeasure and frustration on the part of the students with using the textbook's website. Student displeasure was also communicated through a high number of comments expressed by students to the course director through informal discussions either in the classroom or during office hours. Much of the feedback (formal and informal) from the prior semesters centered on two aspects, the timing of the assignments and the type of questions asked. In terms of the type of questions, the quantitative questions were very frustrating for the students. If they followed the correct process to solve the problem but were just slightly off on the answer due to rounding of decimals, they would be marked wrong and receive no credit. This response is similar to that found in a study of online textbook use at the California Polytechnic State University which found that "student's negative view of...the frustrations with technical problems or answer formatting" [3] This same study found that students had a more favorable view of the use of online textbooks with more qualitative courses.

Not captured in the performance data or the student feedback was the experience of the professor. The difficulty in trying to manage extensions if students were unable to complete 
assignments on time or if there was an issue with the internet or access to the website (which does occur occasionally at USMA).

Improved iteration of implementation of the textbook companion website

This general displeasure and frustration led the course director to implement changes to the utilization of the textbook's companion website over the next three semesters (Academic Terms 17-1, 17-2, and 18-1). The first improvement centered on the timing of the due dates for the online assignments. Rather than grouping several lessons into a block due just prior to an exam, each online assignments would be due the morning its associated lesson was taught. This would force students to read and complete the assignment prior to each lesson. They would then be familiar with the material for the actual lesson being taught rather than using the assignment as a review. "Study questions intended to guide the student's reading are often helpful and prequestions focusing on material at the top of the organizational structure (big ideas, for example) facilitated learning...You need questions that get students to think about the material." [2] This change in linking the assignment to the reading due for that lesson matches well with Just In Time Teaching where "students come to class having put effort into understanding the course material on their own, and with questions about application rather than basic knowledge." [4]

Secondly, to eliminate the frustration surrounding quantitative questions, the questions for the online assignments, would be limited to those focused on the major qualitative concepts in the lesson reading and assessed through five to ten multiple choice questions, which falls in line with the finding from the California Polytechnic State University. [3]

The third major change to the implementation was how students would earn their points on these assessments. Students would be assessed on completion, not correctness of 20 of the 25 online assignments. As long as they attempted the questions for the assignment, they would get full credit. The companion website's gradebook made this assessment easy by distinguishing between a student answering all questions wrong (resulting in a score of 0 ) and a student not attempting the assignment (denoted by a dash - in the gradebook). Students had three opportunities to answer each question. To receive the full point value attached to the online assignments, students only needed to complete 20 of the 25 assignments (80\%). Students earned 5 points for each assignment completed (scaled to 125 points for AT17-1 and 100 point maximum for AT17-2 and AT18-1). Students did not earn extra credit for completing more than 20 assignments. This provides students some flexibility if they miss an assignment due to legitimate reasons such as an internet or other information technology issues, are traveling for academic or athletic evets, or have other competing demands.

To assist students with preparation for exams, the course director set up the assignments so that the questions, answers, and supporting links to the textbook could be viewed after the grading period closed. That way the online assignments became a student resource (as well as a source of questions) for the exams. 


\section{Assessment}

Table 3 summarizes the raw scores, the average number of assignments completed by the students and the average points earned (note, the difference between the raw score and the points earned is that the points earned is calculated by multiplying the number of assignments completed, up to a maximum of 20) by 5 points. As shown in Table 3, the study found that even though students were assessed solely on completion of the assignment and no longer on the correctness of their answers, the average of the students' raw score increased in the improved iteration compared to the initial iteration where points were earned based on correctness. They also completed a higher percentage of the assignments.

\begin{tabular}{|c|r|r|r|}
\hline \multicolumn{5}{|c|}{ AT17-1 (Fall 2016) } \\
\hline \multirow{2}{*}{ Max } & Cumulative Raw Score & Total Assignments & Cumulative Points Assigned \\
\hline \multirow{2}{*}{ Average } & 160 & 25 & 125 \\
\cline { 2 - 5 } & 123.88 & 19.51 & $89.81 \%$ \\
\hline \multicolumn{5}{|c|}{ AT17-2 (Spring 2017) } \\
\hline \multirow{2}{*}{ Max } & Cumulative Raw Score & Total Assignments & Cumulative Points Assigned \\
\hline \multirow{2}{*}{ Average } & 149 & 25 & 100 \\
\cline { 2 - 5 } & 115.17 & 20.29 & 92.20 \\
\hline & $77.29 \%$ & $81.17 \%$ & $92.20 \%$ \\
\hline \multirow{5}{*}{ A } & \multicolumn{5}{|c|}{ AT18-1 (Fall 2017) } \\
\hline \multirow{2}{*}{ Max } & Cumulative Raw Score & Total Assignments & Cumulative Points Assigned \\
\hline \multirow{2}{*}{ Average } & 219 & 25 & 100 \\
\cline { 2 - 5 } & 171.32 & 21.29 & 93.90 \\
\hline
\end{tabular}

Table 3. Improved Iteration Student Performance Data

The professor utilized the same mid-course and end of course feedback mechanisms as during the first two semesters of the initial iteration of the companion website. As evidenced by the data in Table 4, there was an increase in positive comments and a large decrease in negative comments for the improved iteration of implementation. A sampling of the feedback follows. 


\begin{tabular}{|c|c|c|c|c|c|c|}
\hline \multirow[b]{3}{*}{ AT17-1 } & \multicolumn{3}{|c|}{ Mid-Course Feedback } & \multicolumn{3}{|c|}{ End of Course Feedback } \\
\hline & \multirow{2}{*}{$\begin{array}{c}\text { Responses } \\
38\end{array}$} & \multicolumn{2}{|c|}{ Rate } & Responses & \multicolumn{2}{|c|}{ Rate } \\
\hline & & Overall & Split & \multirow{4}{*}{\multicolumn{3}{|c|}{ No data collected }} \\
\hline Positive/Sustain & 4 & $10.53 \%$ & $36.36 \%$ & & & \\
\hline Negative/Improve & 7 & $18.42 \%$ & $63.64 \%$ & & & \\
\hline Total & 11 & $28.95 \%$ & & & & \\
\hline AT17-2 & 46 & Overall & Split & 43 & Overall & Split \\
\hline Positive/Sustain & 4 & $8.70 \%$ & $57.14 \%$ & 3 & $6.98 \%$ & $75.00 \%$ \\
\hline Negative/Improve & 3 & $6.52 \%$ & $42.86 \%$ & 1 & $2.33 \%$ & $25.00 \%$ \\
\hline Total & 7 & $15.22 \%$ & & 4 & $9.30 \%$ & \\
\hline AT18-1 & 39 & Overall & Split & 37 & Overall & Split \\
\hline Positive/Sustain & 2 & $5.13 \%$ & $66.67 \%$ & 0 & $0.00 \%$ & $0.00 \%$ \\
\hline Negative/Improve & 1 & $2.56 \%$ & $33.33 \%$ & 1 & $2.70 \%$ & $100.00 \%$ \\
\hline Total & 3 & $7.69 \%$ & & 1 & $2.70 \%$ & \\
\hline
\end{tabular}

Table 4. Improved Iteration Feedback Summary

"[The companion website] does help get me into the book and not worrying about getting it $100 \%$ accurate is nice. It serves a purpose but isn't frustrating."

"[The companion website] is good to show the most important concepts."

"I like the online homework."

"[The companion website] isn't too hard. It makes you read and find the answers."

"[The companion website] HW's. They force me to prepare for the lesson and get an idea of what we'll be doing in class the next lesson."

"[The companion website] policy and textbook."

"More [companion website]."

"I would like to see the [companion website] homeworks continue. They help me comprehend the readings."

There were still some negative comments, though many focused on the USMA network issues rather than the companion site itself.

"[Companion website]...too expensive for little value; mostly a waste of time identifying definitions"

"No [companion website]. I get more out of the readings and class than [companion website]" "I really don't like [companion website] and forget to do it a lot." 
"I would recommend taking away the [companion website] assignments. I do not think that they were necessary to understanding the material and one could just guess the answers."

Additionally, the course director experienced less frustration with administering the online assignments and the overall student comments in informal discussions was much more positive. The professor did not have to try and decide if a student had a legitimate reason for not completing an assignment on time since they had five they could miss and still earn the full credit. There were some students who commented that they did not feel that they got the value out of the companion website for the cost, but those comments were much fewer.

\section{Outcomes}

The changes in the use of the companion site had positive outcomes on student attainment, which increased even though they were assessed on completeness, not correctness. The rate of completion of the assignments increased dramatically. The raw scores also increased, which may be counterintuitive. An early assumption was that students would just click through the online homework knowing that they're not being evaluated on if their answer was correct, only if the assessment was complete. The data shows the contrary. Students actually earned higher raw scores than in the early iterations as shown in Figure 2.

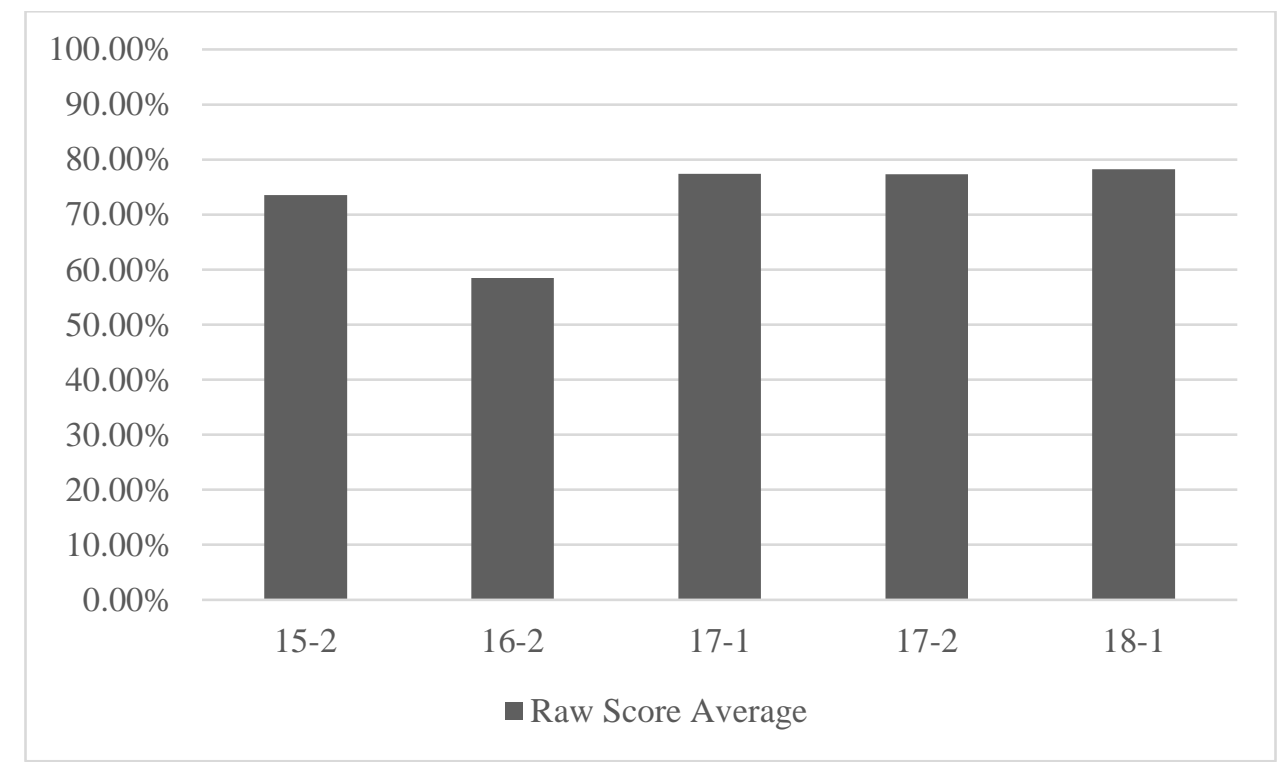

Figure 2. Raw Score Averages (\%) by Semester

Student attitudes towards the utilization of the companion textbook also improved with the implementation of the changes. In the early iterations, there was a much higher rate of responses regarding the use of the companion site, with the majority of the comments being negative. By the last semester of the study, there were very few comments regarding the utilization of the companion website and the few comments were fairly evenly split between positive and negative comments as shown in Figure 3. 


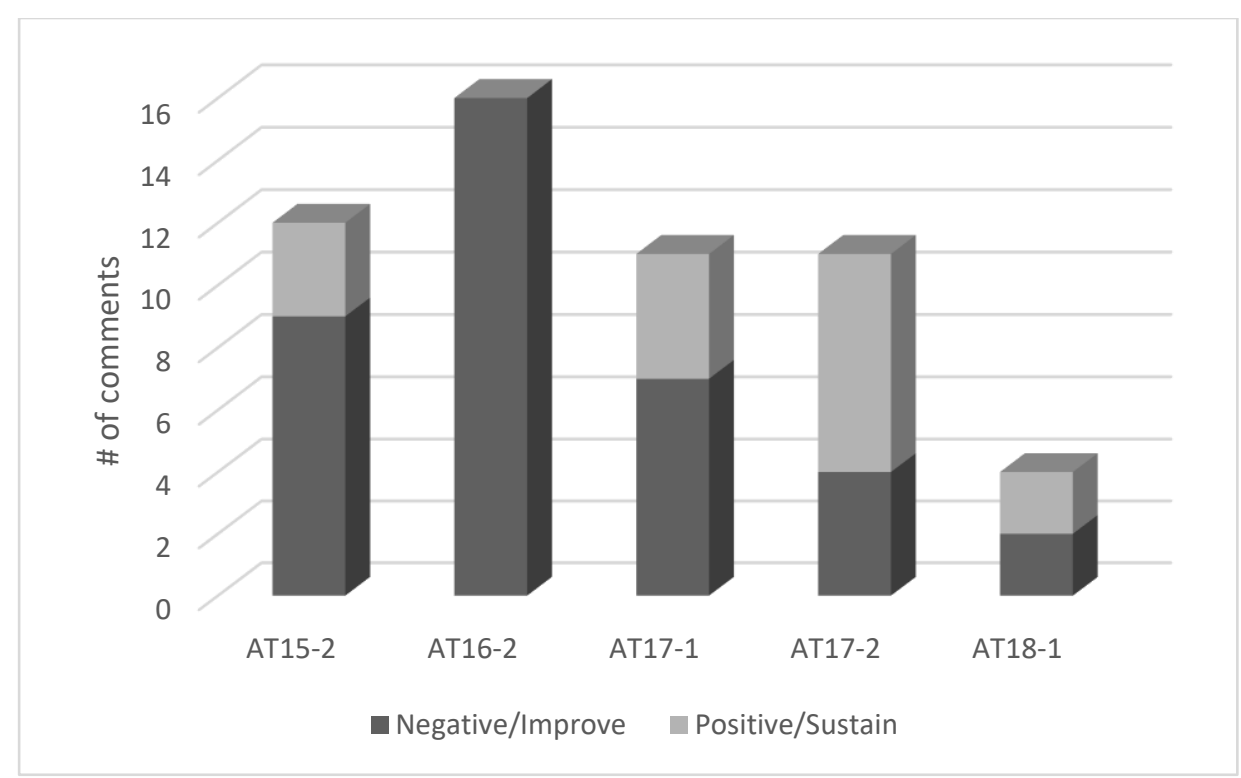

Figure 3. Breakdown of Comments by Semester

Also, student attitudes regarding the use of online assignments were measured during Academic Term 18-1. The 42 students in the course were asked to rate their attitudes using the Likert scale (Table 5) on four questions regarding the helpfulness of online assignments on the first day of the course shown in Table 6. They were asked these same questions on the last day of the course. There was a significant increase in the helpfulness of the online assignments in preparing for class as well as their overall attitude towards online assignments. They were essentially neutral towards the helpfulness of the online assignments in preparing them for the course exams (a mix of qualitative questions similar to what they saw in the online assignments and quantitative questions from the problem sets). The problem sets were mostly quantitative and the questions were not directly related to what the students would have answered in the online assessments. Therefore, it makes sense that there would be a decrease in their assessment of the helpfulness of the online assessments in completing the problem sets and case study.

\begin{tabular}{|c|c|c|c|c|c|}
\hline $\begin{array}{c}1 \text { - Strongly } \\
\text { Disagree } \\
\text { (complete } \\
\begin{array}{c}\text { waste of } \\
\text { time) }\end{array}\end{array}$ & $\begin{array}{c}\text { 2-Disagree } \\
\text { (moderate } \\
\text { waste of } \\
\text { time) }\end{array}$ & $\begin{array}{c}3 \text { - Neutral } \\
\text { difference) }\end{array}$ & $\begin{array}{c}\text { 4-Agree } \\
\text { (somewhat } \\
\text { worthwhile) }\end{array}$ & $\begin{array}{c}\text { N-Strongly } \\
\text { agree } \\
\text { (extremely } \\
\text { worthwhile) }\end{array}$ & $\begin{array}{c}\text { not use the } \\
\text { online } \\
\text { assignments } \\
\text { in this } \\
\text { capacity }\end{array}$ \\
\hline
\end{tabular}

Table 5. Online Assessment Survey Likert Scale 


\begin{tabular}{|l|c|c|c|c|}
\hline AT 18-1 Survey Results (42 responses) & First Class & Last Class & \multicolumn{2}{|c|}{ Delta } \\
\hline $\begin{array}{l}\text { Completing online assignments helped me } \\
\text { prepare for class discussions }\end{array}$ & 3.27 & 3.95 & 0.68 & $20.93 \%$ \\
\hline $\begin{array}{l}\text { Completing online assignments helped me } \\
\text { complete problem sets and/or the case study }\end{array}$ & 3.37 & 3.05 & -0.32 & $-9.45 \%$ \\
\hline $\begin{array}{l}\text { Completing online assignments helped me } \\
\text { prepare for exams }\end{array}$ & 3.17 & 3.12 & -0.05 & $-1.63 \%$ \\
\hline $\begin{array}{l}\text { I have a positive attitude toward completing } \\
\text { online assignments as part of this course }\end{array}$ & 3.27 & 4.10 & 0.83 & $25.30 \%$ \\
\hline
\end{tabular}

Table 6. Online Assessment Survey Results

Another area investigated is student attainment on the online exercises. It would seem that students would be more willing to work hard and try to maximize their scores on each online assignment if each one is going to contribute to their overall grade. And it might be expected to see the scores drop if not all assignments are graded and if their score is solely dependent on completion, not correctness. The data does not align with this expectation. In fact, given more flexibility and connecting each assignment to its particular lesson (rather than waiting until the end of the block) led to a higher completion of the assignments and higher raw scores, meaning the students were putting more time and effort into the online assignments. Many students remarked that they appreciated having the flexibility to not have to complete an assignment if they ran into a technical issue, time management issues, and travel for an athletic or academic trip. It is interesting to note that the raw scores (the number of questions actually answered correctly) increased in the terms where there was more flexibility (scores consistently above $75 \%$ ) compared to the two terms where the requirement was to complete every assignment to get full credit (below 75\%).

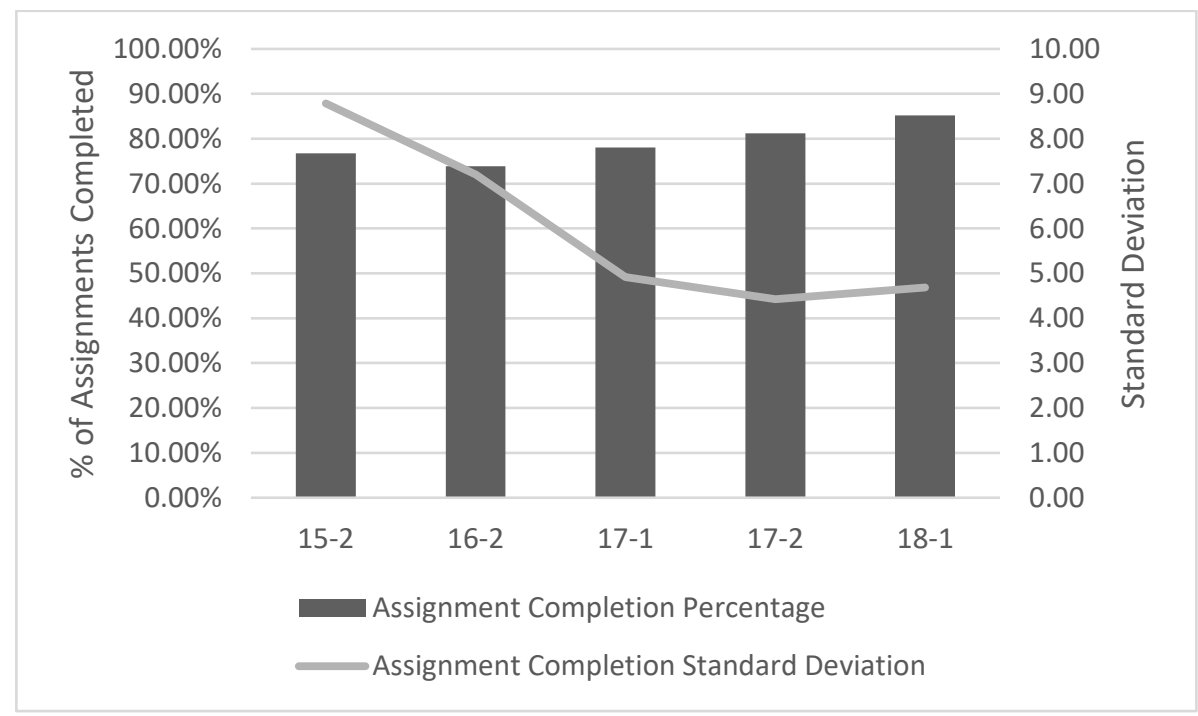

Figure 4. Assignment Completion Rate

Also, the standard deviation of the number of assignments completed decreased with the improvements. Fewer students completed less than $50 \%$ of the assignments under the improved system (from a high of almost 30\% in AT16-2 down to less than 3\% in AT17-2 and 18-1) as well as more completing greater than the $80 \%$ required to receive full credit ( 20 of 25 assignments 
completed to earn 100 points). This demonstrates that students will utilize the resources they see as value added even if they will not directly earn points.

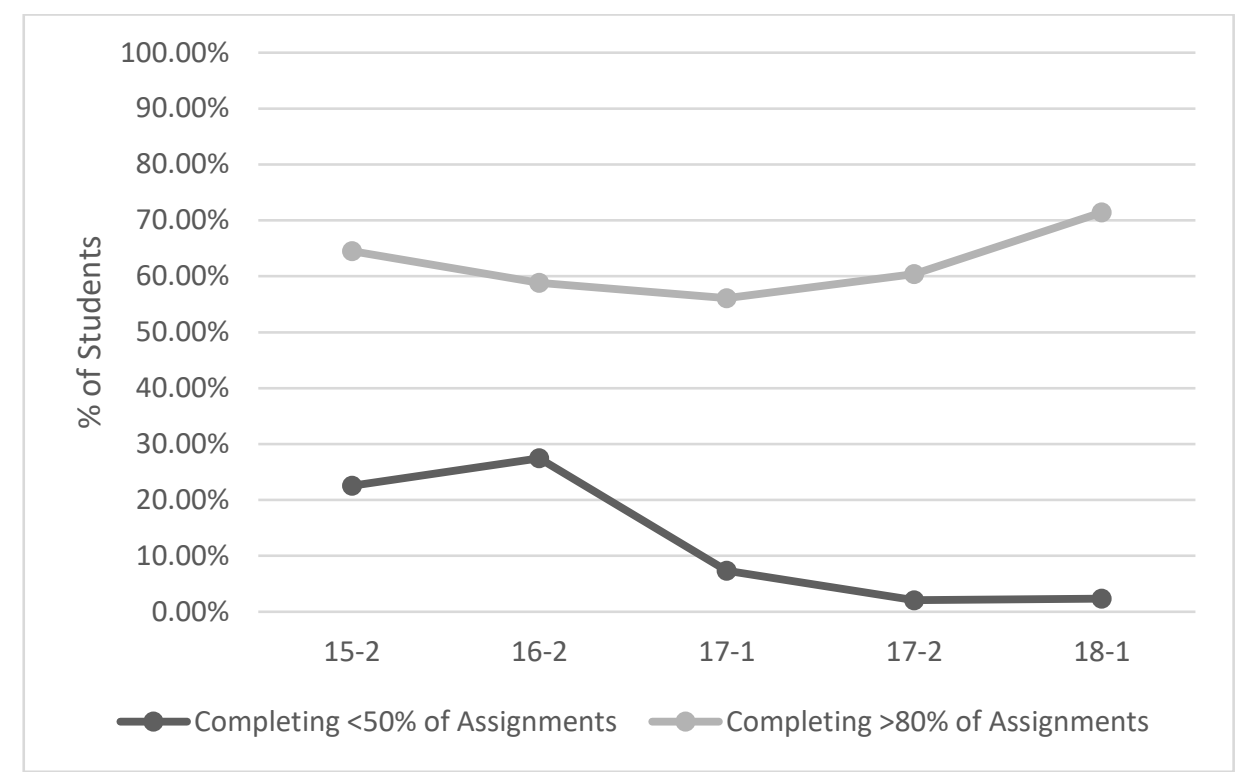

Figure 5. Assignment Completion Thresholds (\%) by Semester

For academic terms 15-2 and 16-2, students needed to complete all assignments in order to receive the maximum credit. In academic terms $17-1,17-2$, and 18-2, students needed to only 20 of the 25 assignments ( $80 \%)$ to get the full credit (100 points) for completing the online assignments. The data shows that a majority of the students in academic terms 17-1, 17-2, and 18-1 completed more than the minimum (20 assignments). This trend aligns well with the decrease in negative student attitudes towards the online assignments, which shows as student attitudes towards the online assignments increased, they saw value in completing the assignment even beyond the minimum threshold. It may also be indicative of them building a habit of completing the assignments as part of their class preparation to be able to contribute in class discussions.

Data on student performance on the exams was collected and evaluated, but no identifiable link or trend between performance and the changes in implementation of the companion website was found. This is not surprising given that in all iterations of implementation of assignments using the companion site the online assignments were available to the students as a resource to support studying for the exams.

Summary and Conclusions

Though not measured, the professor noticed a significant increase in student engagement during the lessons. Having completed the online assignments prior to class, students came in more prepared for discussions, allowing for a richer classroom discussion. Also, the professor was able to cover the concepts and qualitative portions of the lesson material more quickly, allowing more time to discuss the quantitative tools and their application to the concept. The professor also received a much higher number of positive comments and a lower number of negative comments regarding the online assignments, whether through formal or informal forums. The general level 
of frustration and displeasure with these assignments decreases for the students and the professor found it much easier to administer and manage. This discovery is in line with what the Just in Time Teaching found that "instructors, as well as students, find class more enjoyable" [4]

Student feedback has been crucial to improving the implementation of online assignments through the textbook's companion website by changing the scope of the questions from quantitative to qualitative as well as the timing (due for each lesson rather than grouped ahead of an exam). It works very well when used to reinforce key concepts from the reading. This leads to richer classroom discussions as well as the ability to dig quicker and deeper into more difficult and/or quantitative concepts. Also, students respond well to flexibility and the majority will actually achieve more than the minimum standards when they see the value of the online assignments. The improvements in student attitudes and attainment throughout the evolution of the use of the textbook companion site over the course of five semesters of a production operations course bears this out.

The recommendation is that engineering management courses adopt a similar method of implementation of textbook companion websites to improve student engagement and attainment. Other courses in the Engineering Management Program at the United States Military Academy have adopted similar models for implementing their textbook companion websites with anecdotal evidence that the implementation has been similarly successful.

\section{References}

[1] J. Lowman, Mastering the Techniques of Teaching. San Francisco, CA: Jossey-Bass, 1995.

[2] M. Svinicki and W. McKeachie, McKeachie's Teaching Tips. Strategies, Research, and Theory for College and University Teachers. Belmont, CA: Wadsworth, Cengage Learning, 2011.

[3] C. Chen, C. Victorino, C. Birdsong, U. Menon, M. Tseng, and T. Smith, "A Study of On-line Textbook Use Across Multiple Engineering Courses", 2011 ASEE Annual Conference \& Exposition, ASEE 2011, Vancouver, BC, Canada, June 26-29, 2011, pp. 22.109.1-16.

[4] A. Szmerekovsky, B. Self, "Using Just-in-Time Teaching in Dynamics and in Mechanics of Materials", 2006 ASEE Annual Conference \& Exposition, ASEE 2006, Chicago, IL, USA, June 18-21, 2006, pp. 11.1392.1-14. 